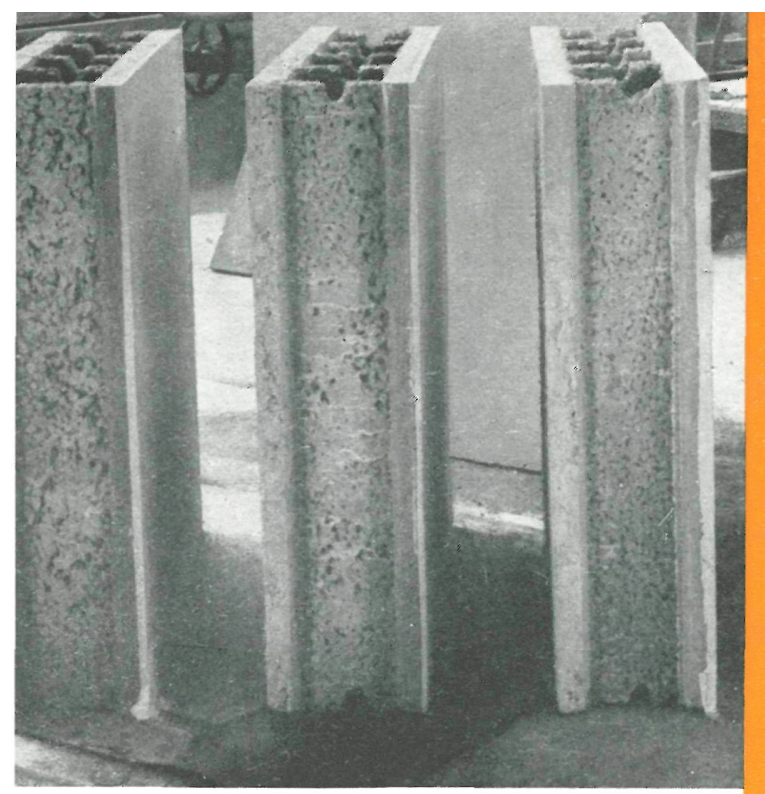

\title{
bloques de hormigón para muros
}

JOSÉ MARÍA EYMAR, ayudante de obras públicas

$686-2$

En el Instituto Técnico de la Construcción y del Cemento se están llevando a cabo una serie de ensayos sobre un tipo de bloque semipesado de hormigón, al que se ha llegado después de diversas modificaciones y tanteos. Estos bloques pueden fabricarse a pie de obra, ya que para su ejecución se emplean unos moldes sumamente sencillos, robustos y fácilmente transportables, y no se necesitan como instalaciones fijas más que una solera de hormigón. La mano de obra no es necesario que sea especializada, y en todo caso en una sola jornada puede quedar el personal obrero totalmente enterado y dispuestos a ejecutar el moldeo. Los precios obtenidos son inferiores a los de un muro de ladrillo de $25 \mathrm{~cm}$, enfoscado en su cara externa y guarnecido de yeso en la interna.

(1)

כ

$\sigma$

O

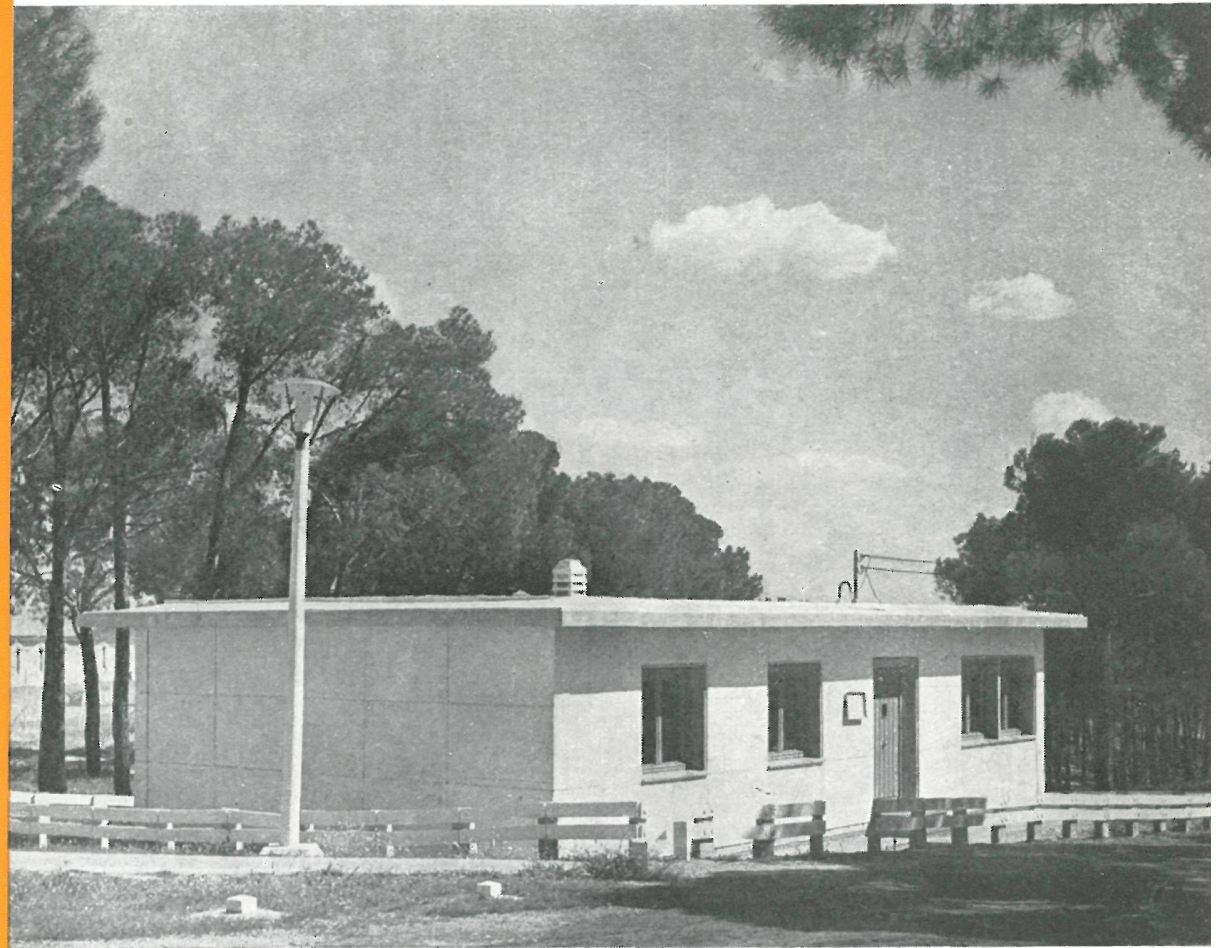

PIELAS DE HORMIGON SIN FINOS

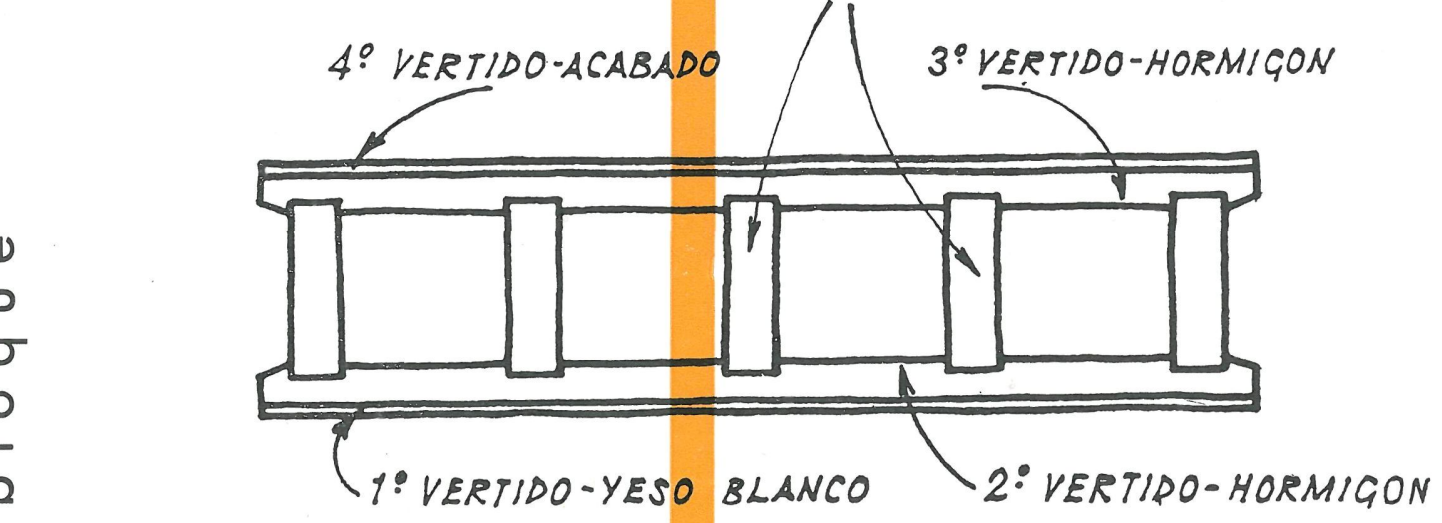



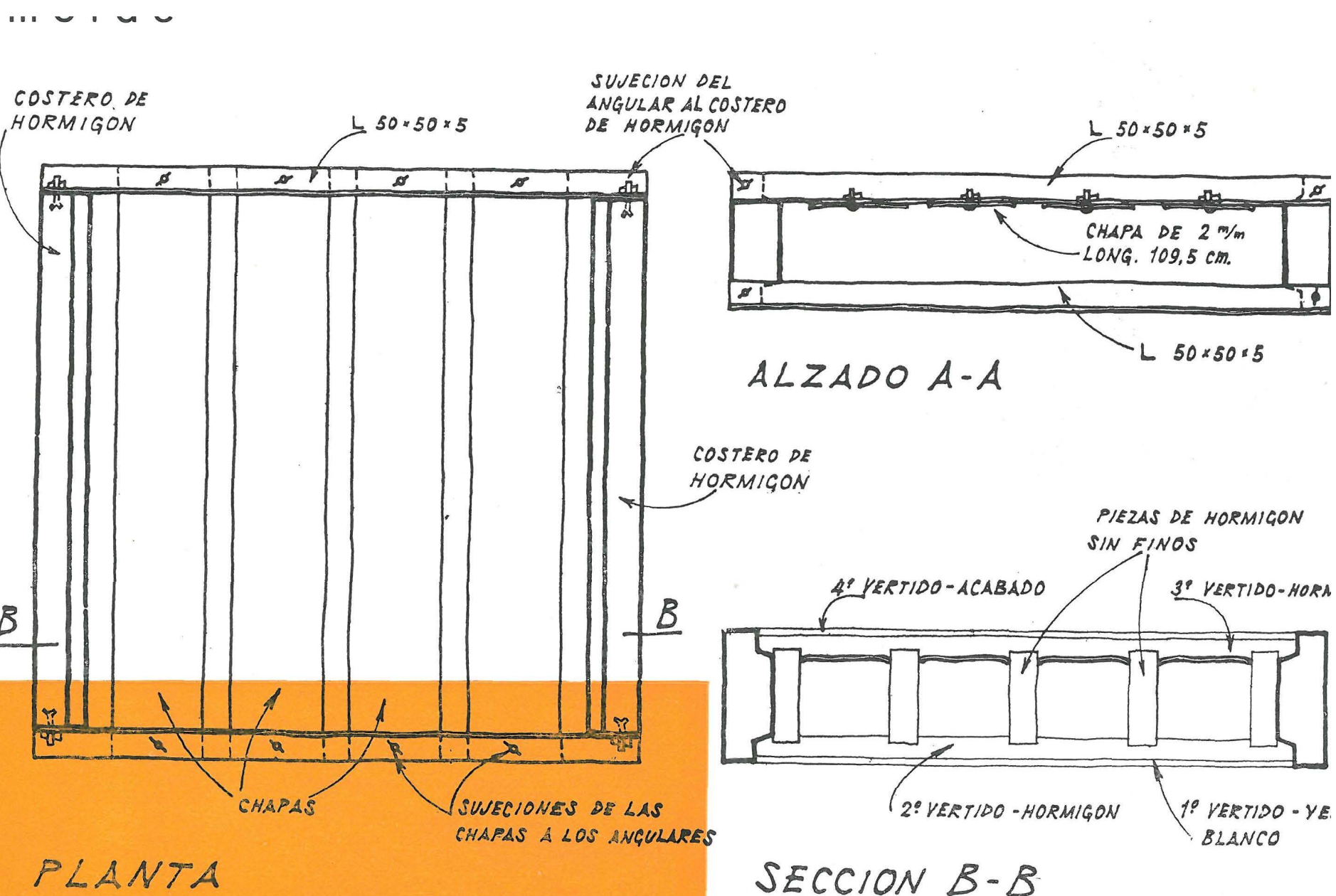

SECCION B-B

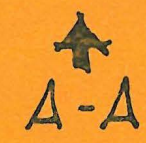

Las dimensiones de los bloques pueden ser elegidas por el constructor, indicándose más adelante, y a título de orientación, las dimensiones y pesos de los bloques ensayados, siendo el objeto de este artículo dar a conocer el tipo de bloque y algunos de los resultados obtenidos hasta la fecha.

\section{Composición del bloque}

El bloque está constituído por dos paneles paralelos de hormigón, unidos entre sí por unas piezas rectangulares de hormigón sin finos y formando el conjunto un bloque hueco con conductos en una sola dirección. De las dos caras del bloque, la que constituye la externa del muro está acabada con mortero de cemento, y la interna en yeso blanco: tanto una como otra quedan después de la fabricación del bloque dispuestas para pintura.

Los bloques hasta ahora ensayados tienen las dimensiones y características siguientes:

$\begin{array}{lccccccc} & \begin{array}{c}\text { A L T } \\ (\mathrm{cm})\end{array} & \begin{array}{c}\text { A N C H } \\ (\mathrm{cm})\end{array} & \begin{array}{c}\text { Espesor } \\ \text { Total } \\ (\mathrm{cm})\end{array} & \begin{array}{c}\text { N.o de piezas } \\ \text { de hormigón } \\ \text { sin finos }\end{array} & \begin{array}{c}\text { Grüeso } \\ \text { de paredes } \\ (\mathrm{cm})\end{array} & \begin{array}{c}\text { Peso } \\ \text { del bloque } \\ (\mathrm{kg})\end{array} & \begin{array}{c}\text { Peso por m² } \\ \text { de muro } \\ (\mathrm{kg})\end{array} \\ \text { BLOQUE I } & 99,5 & 99,5 & 25 & 5 & 5 & 300 & 303 \\ \text { BLOQUE II } & 86 & 129,5 & 25 & 6 & 5 & 340 & 306 \\ \text { BLOQUE III } & 86 & 129,5 & 25 & 6 & 3 & 265 & 238\end{array}$


Detalle de juntas

Esquina.

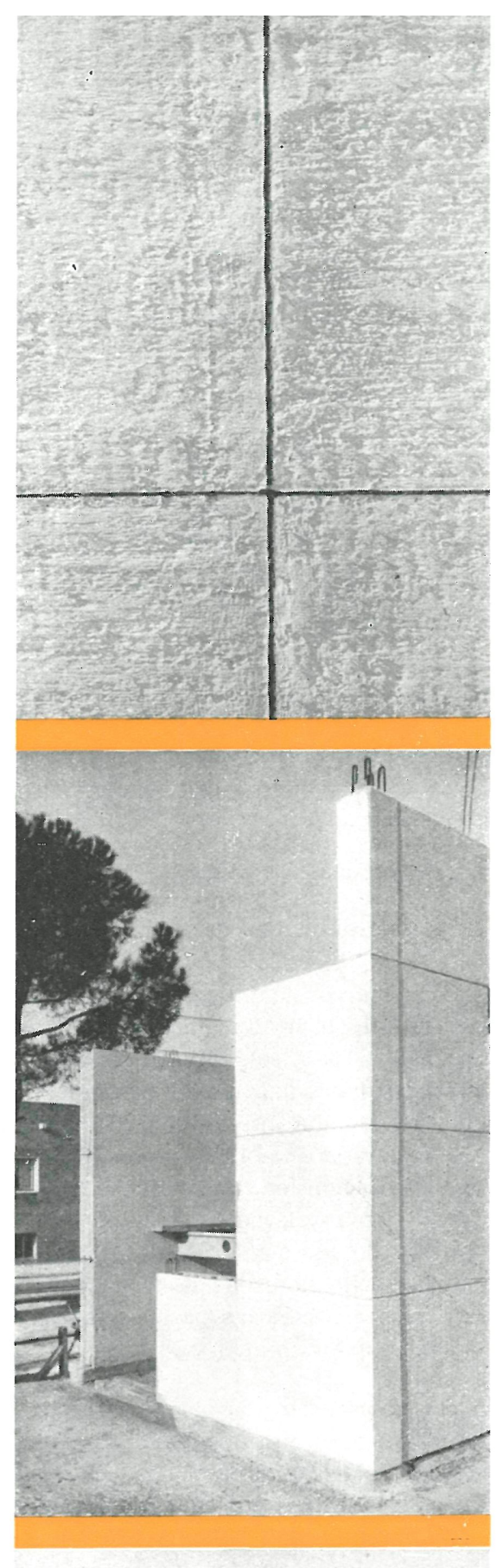

\section{Composición del muro}

Los bloques quedan recibidos entre sí y por sus juntas horizontales por medio de mortero de cemento, que se coloca con paleta en los bordes de los paneles de un bloque antes de la colocación del bloque inmediato superior, el cual, por su propio peso, comprime el mortero, procediéndose seguidamente a retirar el sobrante. Una vez colocados todos los bloques de una hilada se hormigonan los huecos que quedan entre bloques utilizando un hormigón seco, con lo que se evitará que salga lechada por la junta vertical. Los pilarcillos así formados han de tener las juntas de construcción a unos 20 centímetros del enrase de cada hilada, a fin de evitar que toda la junta horizontal del muro sea continua. Estos pilares pueden armarse todos o solamente los que se estimen necesarios.

El repaso de juntas exteriores es innecesario si se procede como se ha indicado. El de las juntas interiores se hará con yeso blanco.

En la primera hilada de bloques, es decir, la que arranca de cimientos, se creyó conveniente prever la ventilación interior del muro, así como la evacuación de aguas que, pasando del primer panel, bajasen por su cara interna. Para ello se utilizó una pieza prefabricada de hormigón, recibida a la cara superior del muro de cimentación; si bien posteriormente se comprobó que bastaba disponer unas ranuras transversales en el mismo muro de cimentación, con lo cual quedaba garantizada la ventilación necesaria para secar las ligeras humedades de la cara interior del panel.

\section{Resistencia, impermeabilidad, aislamiento térmico}

Las series de bloques rotos a compresión fueron constituídas por bloques fabricados en distintas jornadas y con edades que oscilaban entre los 15 y los 20 días. Previamente, se les hormigonó uno de los conductos y fueron sometidos a carga centrada en el pilar así formado, obteniendo como carga da rotura característica 70 toneladas.

Para ensayar el comportamiento del bloque a efectos de humedades en la cara exterior, fué sometido un muro formado de bloques del tipo I a la acción de un chorro de agua en distintas zonas, incluso juntas, durante ocho horas en cada una de ellas, observándose muy ligeras humedades en algunos puntos de la cara interna del panel exterior y ausencia absoluta de humedades en el panel interior.

El aislamiento térmico de bloques de los tipos I y II es el mismo que el que se obtiene con 28 cen-

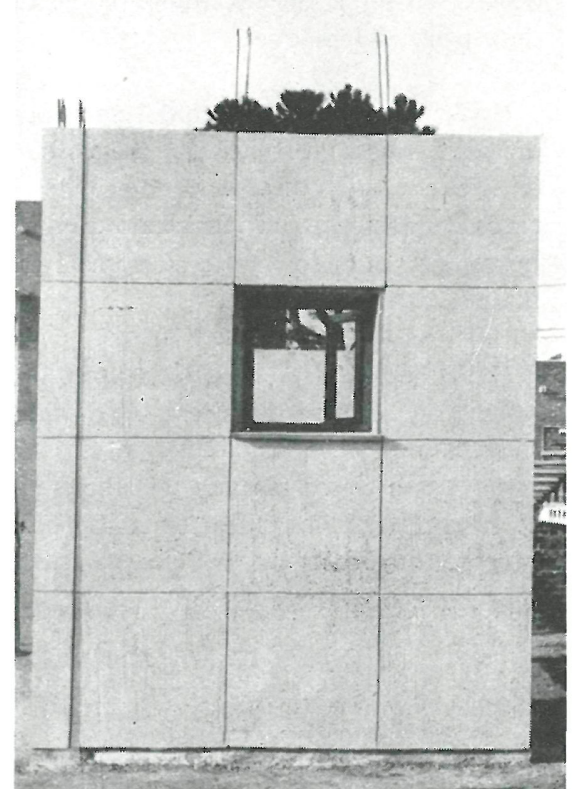


Ensayo a com. presión.
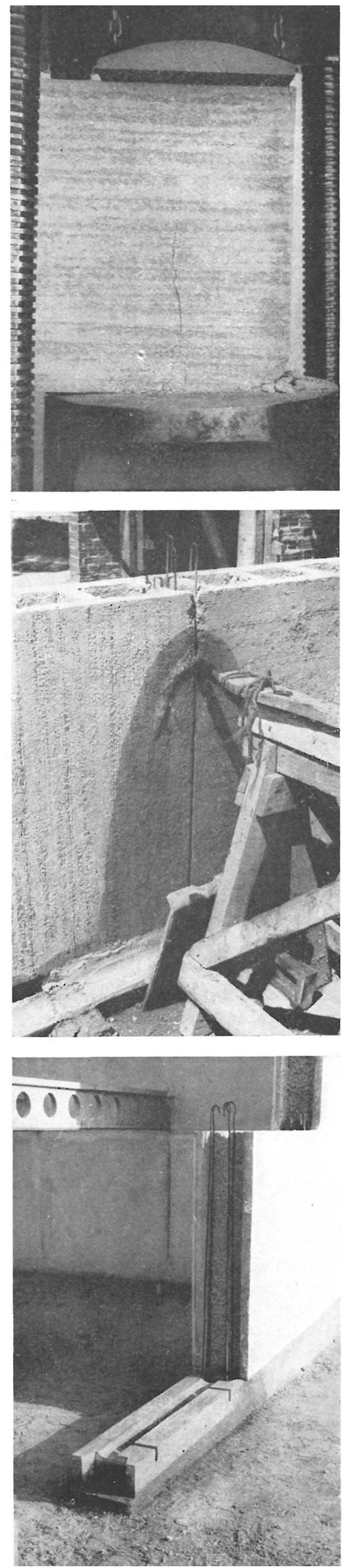

tímetros de ladrillo macizo. Puede aumentarse en caso necesario introduciendo en los huecos del bloque cualquier material aislante.

\section{Fabricación de bloques}

Esta fabricación puede llevarse a cabo sin necesidad de elementos auxiliares costosos y sin mano de obra especializada. Los elementos necesarios para una producción de 16 bloques diarios del tipo II son:

6 marcos metálicos para moldeo de piezas de hormigón sin finos;

16 moldes mixtos de hormigón y perfiles laminados;

32 planchas de goma de $1,30 \times 1,30$ metros, $y$

32 soleras planas de hormigón.

Los marcos metálicos para el moldeo de piezas de hormigón sin finos constan de cuatro angulares de $50 \times 50 \times 5$, soldados en esquinas. El desmoldeo es inmediato; las piezas permanecen en el banco de trabajo durante veinticuatro horas, al cabo de las cuales pasan a almacén, donde son regadas hasta su utilización en la fabricación del bloque. Esta operación es llevada a cabo por un equipo, compuesto de un ayudante y un peón ordinario, que en las ocho horas de la jornada normal preparan las piezas necesarias para la fabricación de los 16 bloques que se han fijado como producción.

La fabricación del bloque se realiza del siguiente modo: sobre una plancha de goma se arma el molde, constituído por dos costeros de hormigón paralelos unidos por cuatro angulares (dos de estos angulares quedan descansando sobre la plancha de goma y los otros dos junto con la parte superior de los costeros de hormigón constituyen el plano de enrase del bloque).

Una vez armado el molde, se procede al vertido de yeso hasta formar una capa de 1 centímetro de espesor, pero practicándole antes de que endurezca totalmente un enrasado rugoso para que el hormigón que se vierte después quede perfectamente adherido.

Seguidamente, se vierte y apisona una capa de hormigón, enrasándola con los costeros inferiores metálicos para, a continuación, sujetar a los costeros superiores las chapas metálicas entre las cuales se introducen las piezas de hormigón sin finos, presionándolas a fin de que se introduzcan en la masa vertida anteriormente. 
Molde.

Vertido de yeso.

Enrasado de yeso.

Vertido primera capa de mortero.

Golocación de chapas.
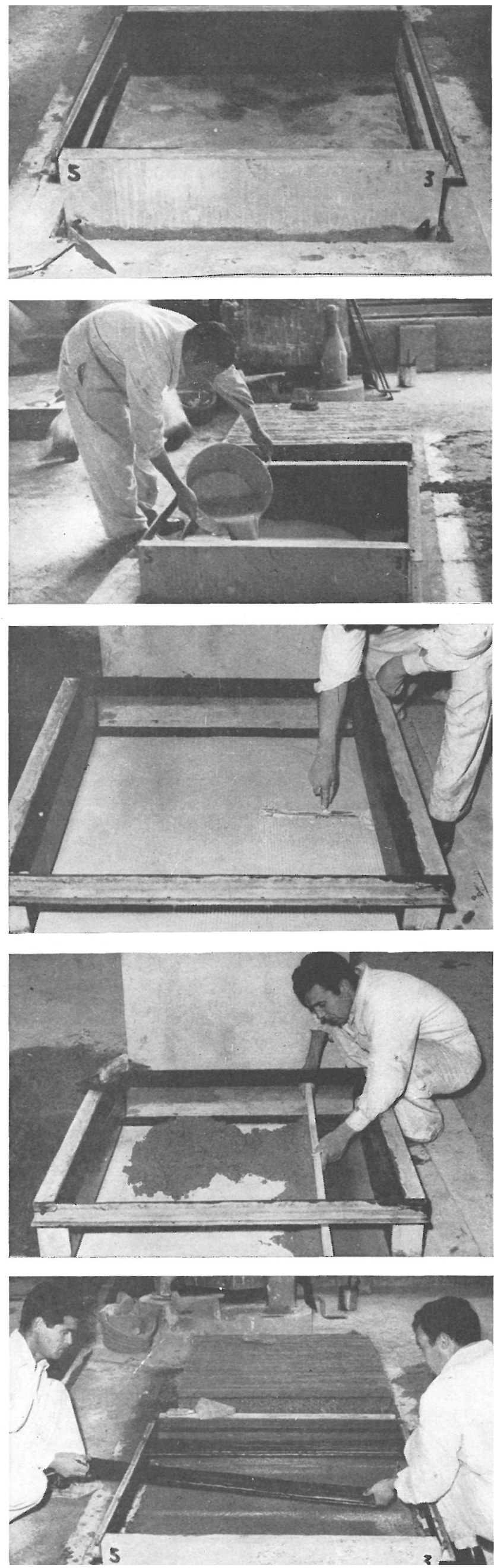

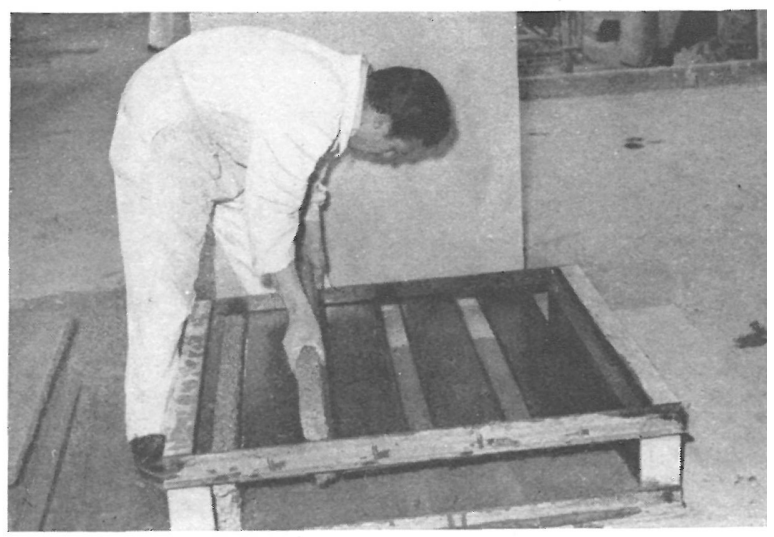

Colocación de las piezas de hormigón sin finos.

La operación de moldeo se concluye con el vertido de otra capa de hormigón, que queda sostenida por las chapas metálicas y que enlaza las piezas de hormigón sin finos. Seguidamente, se procede al acabado de superficie en la forma que se desee.

El desencofrado se realiza a las veinticuatro horas, incluso con temperaturas medias de $8^{\circ} \mathrm{C}$; pero siempre el bloque ha de quedar sobre la plancha de goma durante otras veinticuatro horas, al cabo de las cuales se puede manejar y situar en almacén en espera de ser colocado en obra. El desencofrado se inicia retirando chapas; se continúa quitando costeros metálicos, y concluye al ser separados los dos costeros de hormigón.

Las operaciones indicadas pueden realizarse por un ayudante y un peón ordinario, que en la jornada normal de ocho horas ejecutan los 16 bloques.

\section{Mano de obra y materiales invertidos}

A continuación se relaciona la mano de obra necesaria, los materiales invertidos y las amortizaciones que habrán de ser previstas para la fabricación y colocación en obra de un bloque tipo II (ver características en el (uadro). Si a las partidas que se reseñan se les aplica los precios que cada constructor estime oportunos, se obtendrá el precio de ejecución material, siempre que el taller de fabricación esté situado a una distancia máxima de 100 metros del lugar de colocación en obra. 
Vivienda unifamiliar con muros de bloques tipo II en fase de construcción.

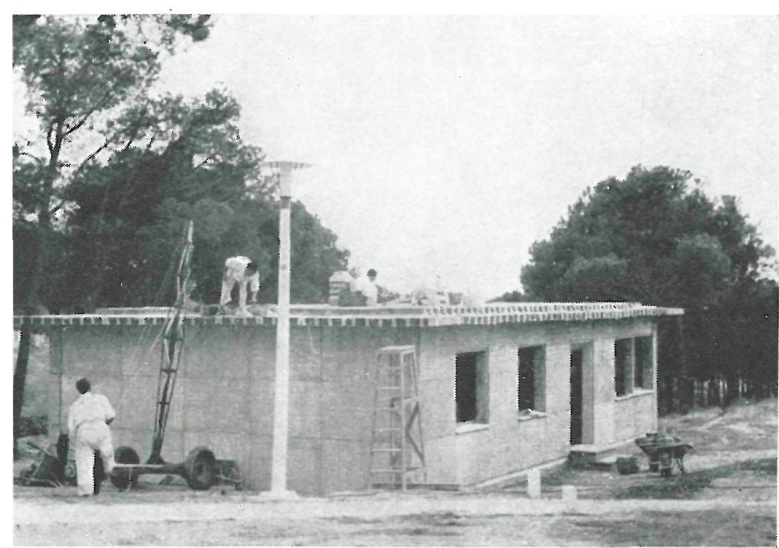

Fotos: M. GARCIA MOYA

M A T E R I A L E S

En seis piezas 8 kilos de cemento gris de hormigón $\left\{\begin{aligned} 50 & \text { litros de piñoncillo, con ta } \\ & \text { maños comprendidos entre } 10\end{aligned}\right.$ $\sin$ finos ....

En el moldeo $\left\{\begin{array}{l}10 \text { kilos de yeso blanco. } \\ 15 \text { litros de arena de río. }\end{array}\right.$ del bloque... 68 litros de gravilla.

28 kilos de cemento gris.

En colocación $\begin{array}{r}12 \text { litros de arena de río. } \\ 9 \text { litros de gravilla. }\end{array}$

en obra ...... 6 kilos de cemento gris. 4 kilos de yeso blanco.

\section{MANO DE OBRA}

En seis piezas 0,50 horas de ayudante. de hormigón 0,50 horas de peón ordinario. sin finos .... 0,10 horas de jefe de equipo.

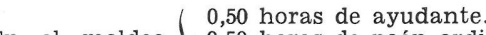
de un bleo 0,50 horas de peón ordinario. 0,10 horas de jefe de equipo.

( 0,20 horas de oficial $1 . .^{\mathrm{a}}$

En colocación 0,20 horas de ayudante. en obra ..... 0,05 horas de encargado.

En transportes $\{0,50$ horas de peón ordinario.

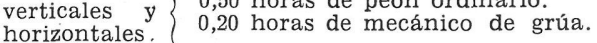

V A R I O S En taller …... $\begin{aligned} & \text { Amortización de moldes. } \\ & \text { Amortización de naves. } \\ & \text { Grasas, herramientas, etc } \\ & \text { Imprevistos. }\end{aligned}$

En obra ….... $\left\{\begin{array}{l}\text { Amortización de grúa. } \\ \text { Reparaciones, energía. } \\ \text { Imprevistos. }\end{array}\right.$

Todos estos rendimientos y gastos de materiales se han tomado de una serie de 200 bloques. Parte de ellos se han utilizado para la construcción de una vivienda unifamiliar, actualmente en período de observación.

NFORMES DE LA CONSTRUCCION 101

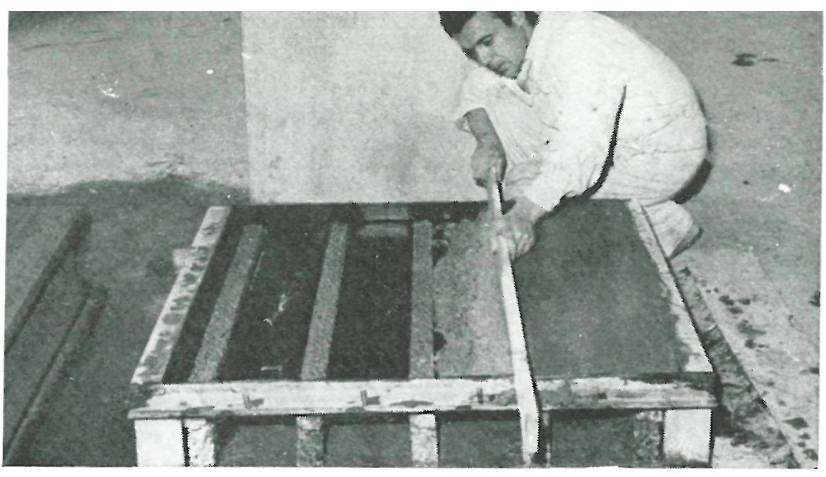

Vertido de la se gunda capa

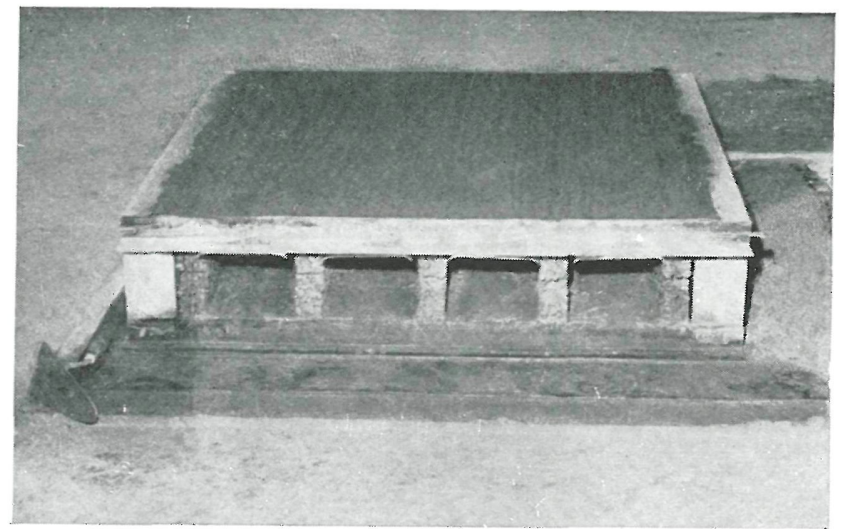

Un bloque er molde.

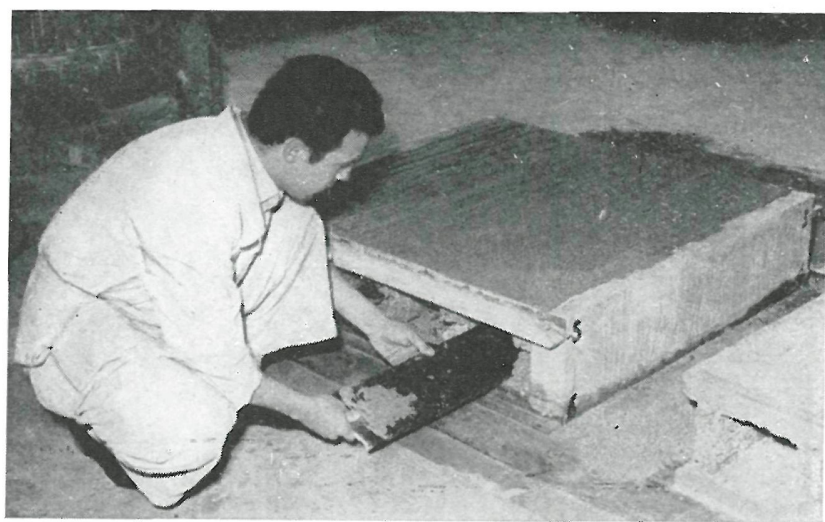

Retirando chapas.

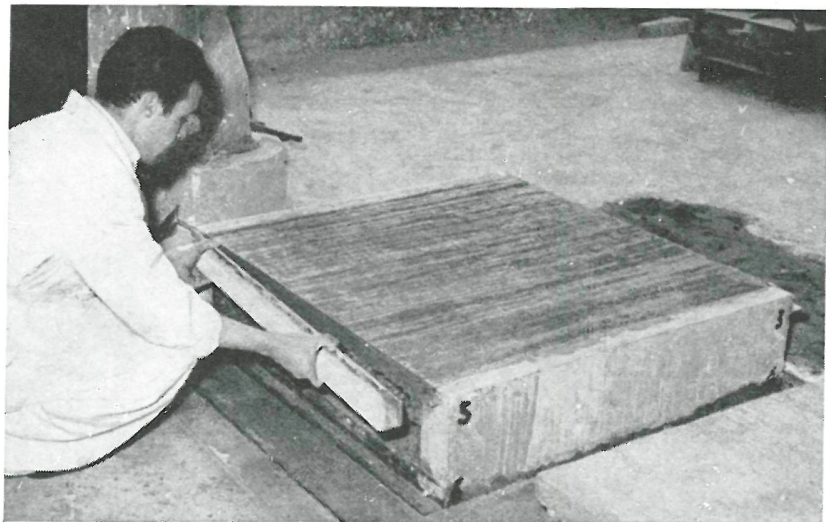

Retirando coste. ros metalicos.

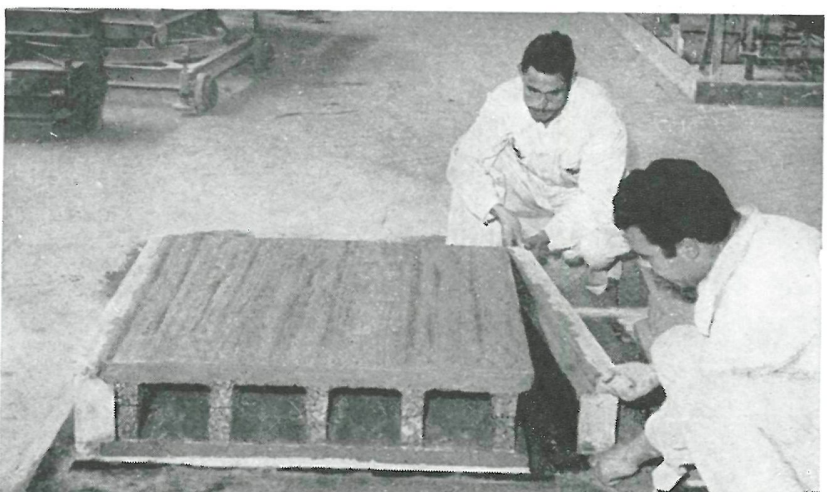

Retirando coste 